Mahmood : Effect Of Types Of Bearing On The Load Distribution Among Girders

\title{
Effect Of Types Of Bearing On The Load Distribution Among Girders Of The Bridge
}

\author{
Dr. Mohammad N. Mahmood \\ Assistant professor \\ Assistant Lecturer
}

Civil Engineering Department

Mosul University

\begin{abstract}
The present paper involves three-dimensional nonlinear analysis for reinforced concrete bridge deck consisting of three main girders. Finite brick element is used to predict response of the bridge under monotonically increasing static loads up to failure.

A main concern is given to the effects of boundary conditions at the supports, and their effects on the behaviour of the bridge. Three types of supports were considered, these are simple support, elastomeric pads and a simple springs. The study includes also the effect of boundary conditions on the failure load, the load distribution amongst the main girders, and variation of bearing reactions in both pre and post cracking phases. The study shows that the method of representing the supports significantly affects the distribution of the loads among the main girders of the bridge.
\end{abstract}

Key Words : Bearings, Bridge, Finite Element, Load Distribution, Nonlinear Analysis, Reinforced Concrete.

$$
\text { د. تأثير انواع المساند في توزيع الأحمال بين روافد الجسر }
$$$$
\text { مدرس مساعد }
$$

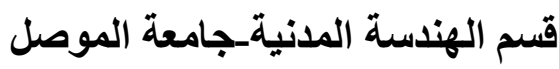


Mahmood : Effect Of Types Of Bearing On The Load Distribution Among Girders

\section{الخلاصة}

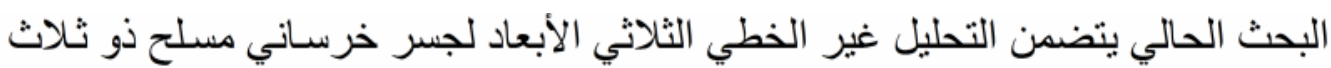

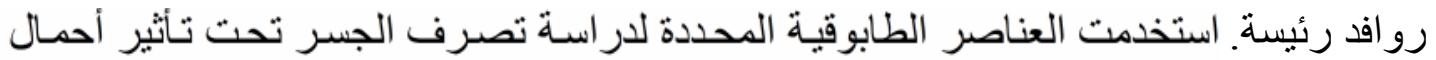

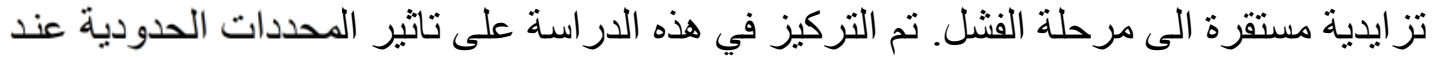

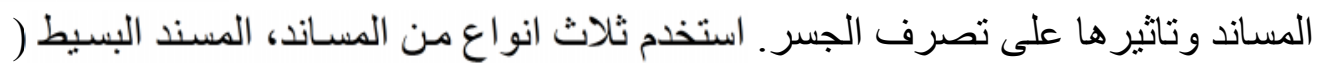

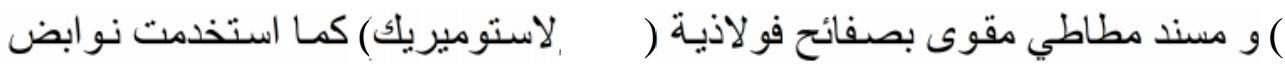

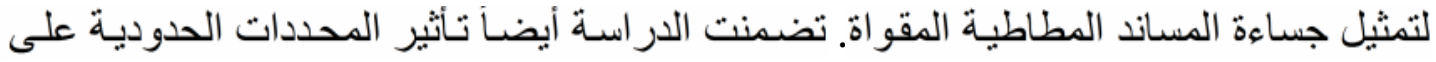

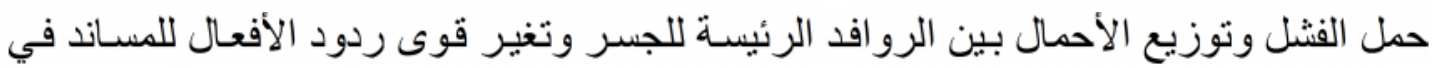

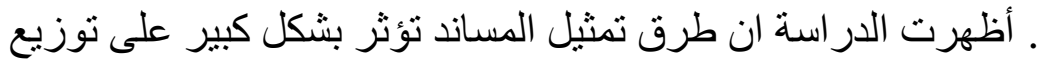

الأحمال بين الرو افد الرئيسة للجسر.

Received 25 August. 2005

Accepted 20 July 2006

\section{Notations}

A Loaded area

[B] Strain-displacement matrix

[D] Elasticity constitutive matrix of concrete

[D $\mathbf{D}_{\mathbf{s}}$ Elastic or elasto-plastic material matrix of smeared steel layer

$\mathrm{d}_{\mathrm{c}}, \mathrm{d}_{\mathrm{s}}$ Compression and Shear displacement

$\mathrm{E}_{c} \quad$ Initial modulus of elasticity of concrete

$\mathrm{E}_{\mathrm{s}} \quad$ Initial modulus of elasticity of steel

$\mathrm{E}_{\mathrm{o}} \quad$ Young's Modulus of rubber

$\mathrm{F}_{\mathrm{c}} \quad$ Applied force in the compression direction

$\mathrm{F}_{\mathrm{s}} \quad$ Applied force in the shear direction

$\mathrm{f}_{\mathrm{c}}^{\prime}, \mathrm{f}_{\mathrm{t}}^{\prime} \quad$ Uniaxial tensile and compressive strength of concrete

fy Yield strength of steel

G Shear modulus of rubber

[J] Jacobian matrix

$\left[\mathrm{K}_{\mathrm{T}}\right] \quad$ Global tangent stiffness matrix

$\left[\mathrm{K}_{\mathrm{c}}\right] \quad$ Concrete stiffness matrix

$\left[\mathrm{K}_{\mathrm{s}}\right] \quad$ Steel stiffness matrix 
Mahmood : Effect Of Types Of Bearing On The Load Distribution Among Girders

\section{L.D.F Load distribution factor}

S Shape factor of elatomeric bearing

[T] Transformation matrix from the local to the global system

$$
\xi, \eta, \zeta \quad \text { Curvilinear coordinate }
$$

\section{Introduction}

Finite element method always considered as a powerful and versatile tool for the analysis of complex structures like bridges and it is capable of taken cognizance of material nonlinearly, cracking and the three dimensional nature of the problem.

Bakht and Jaeger [1] used a plane-shell finite element to analyze a steel Igirder bridge for various values of bearing restraints. It has been shown that the main reason that existing bridges appear stiffer than their calculated values is the horizontal restraint offered by girder supports.

Tarhini and Frederick [2] used the finite element method to predict the actual stress distribution and evaluate the load transfer to the beams of a highway bridge from designed vehicle loads.

Mahmood [3] used nine-node shell elements to investigate the true behaviour of reinforced concrete girder bridges under monotonically increasing load up to failure. The study includes also prediction of the distribution of the load amongst the main girders during different stages of loading, variation of the support reactions in the pre and post cracking stages, and the effect of number of cross beams and their locations on the overall response of the bridge.

Kwasniewski [4] presented finite solid element analysis of a deck girder bridge. It was found that the boundary condition at the girder's ends is the most important parameter in the modeling of the actual bridge under service load. Partial constraints at the supports were simulated using spring elements.

In the present study an attempt has been made to investigate the effects of simulation of supports on the overall response of reinforced concrete deck girder bridges under increasing load up to failure. A nonlinear analysis is carried out using 20 node brick finite elements to represent the concrete while reinforcement bars are represented by a smeared layers. Three types of modeling were used to represent the simple supports. 
Mahmood : Effect Of Types Of Bearing On The Load Distribution Among Girders

Materials Modeling

Concrete in compression considered to behave as linear elastic up to about $0.3 f^{\prime}$ 'c followed by plastic response with strain hardening model [5] as shown in Fig. (1). The behaviour of concrete in tension is considered as an elastic linear up to cracking stress. An exponential stress degradation function is used to model the tension stiffening that allows the post-cracking tensile stress in concrete to be retained in the cracked concrete $[6$ stages is us

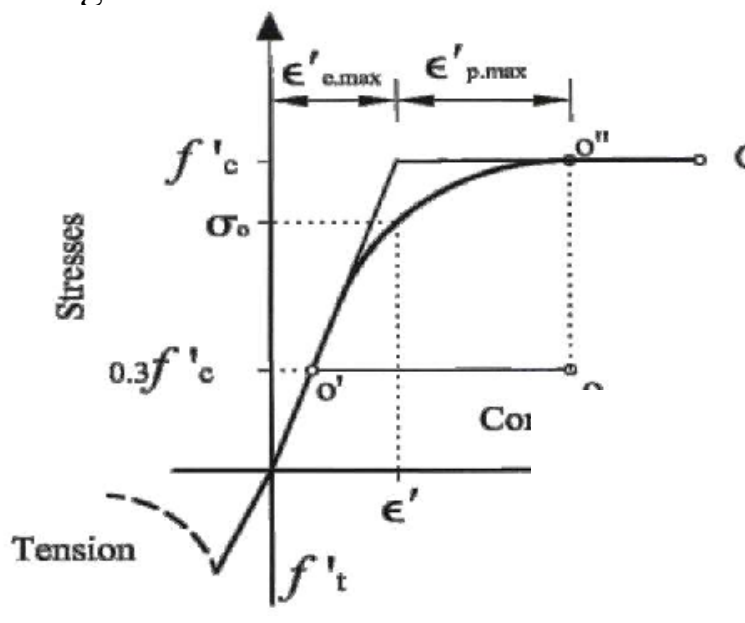
st-cracking Crushing

(Strain Hardening) (Elastic - Perfect Plastic) (Tension Stiffening) - -

Steel Fig. (1) Uniaxial representation of concrete constitutive model.

elastic linear strain hardening material [7].

Rubber, when confined, it is almost incompressible and for practical purposes its volume does not alter under load, therefore for such material to deform under particular loading it must be able to bulge laterally [8] as shown in Fig. (2).

Poisson's ratio $v$ for elastomeric is takes equal to 0.49 [9] and in the present study the following properties has been used to model the material properties

of the elastomer [10,11] :

\begin{tabular}{|c|c|c|c|c|}
\hline $\begin{array}{c}\text { Hardnes } \\
\text { s }\end{array}$ & $\begin{array}{c}\text { Young's } \\
\text { Modulus }\end{array}$ & $\begin{array}{c}\text { Shear } \\
\text { Modulus }\end{array}$ & $\begin{array}{c}\text { Material } \\
\text { Compressibility }\end{array}$ & $\begin{array}{c}\text { Bulk } \\
\text { Modulus }\end{array}$ \\
\hline
\end{tabular}


Mahmood : Effect Of Types Of Bearing On The Load Distribution Among Girders

\begin{tabular}{|c|c|c|c|c|}
\hline IRHD2 & MPa & $(\mathrm{G}) \mathrm{MPa}$ & Coefficient $\varnothing$ & $\left(\mathrm{E}_{\mathrm{b}}\right) \mathrm{MPa}$ \\
\hline 60 & 4.45 & 1.06 & 0.57 & 1150 \\
\hline
\end{tabular}

Finite Element Models

20-node isoparametric brick elements were used to represent the concrete.

The contribution to the stiffness matrix from the solid concrete element is determined by the expression [12]:

$\left[K_{c}\right]=\int_{-1}^{+1} \int_{-1}^{+1} \int_{-1}^{+1}[B]^{T} \cdot\left[D_{c}\right] \cdot[B] \cdot|J| d \xi d \eta d \zeta$

The reinforcement is represented by a smeared layer having thickness equivalent to the area of steel bars, as shown in Fig. (3).

The stiffness contribution of each layer is evaluated by using $(2 * 2)$ Gauss quadrature rule:

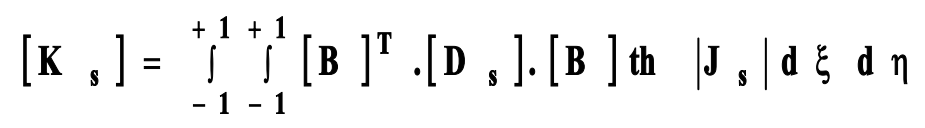

Its stiffness is added to that of the concrete to obtain the total stiffness of the element so that:

$$
\left[\mathbf{K}_{\mathbf{T}}\right]=\left[\mathbf{K}_{\mathbf{c}}\right]+\left[\mathbf{K}_{\mathbf{s}}\right]
$$

Representation of elastomeric Pad bearings:

The elastomeric pad bearing for girder bridges consists of one or more internal layers of elastomer bonded to internal steel laminates of rectangular shape by the process of vulcanization. The components of a typical elastomeric pad bearing are shown in Fig. (4) [8].

In the present study the adopted dimensions of elastomeric pad bearing are:

Plan dimensions $(\mathrm{a} * \mathrm{~b})=300 * 300 \mathrm{~mm}$

Total thickness $(\mathrm{h})=52 \mathrm{~mm}$

Thickness of individual elastomer layer $\left(h_{i}\right)=10 \mathrm{~mm}$ 
Mahmood : Effect Of Types Of Bearing On The Load Distribution Among Girders

No. of internal elastomer layers $\quad=3$

No. of laminates $=4$

Thickness of each laminate $\quad\left(h_{s}\right)=3 \mathrm{~mm}$

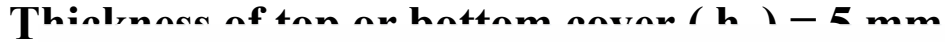

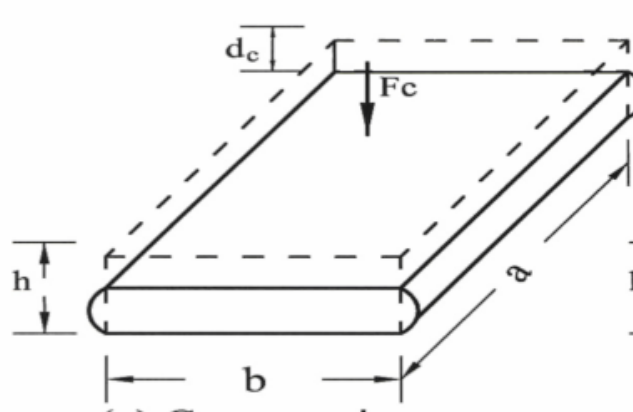

(a) Compressive Force

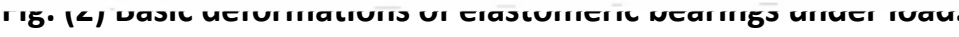

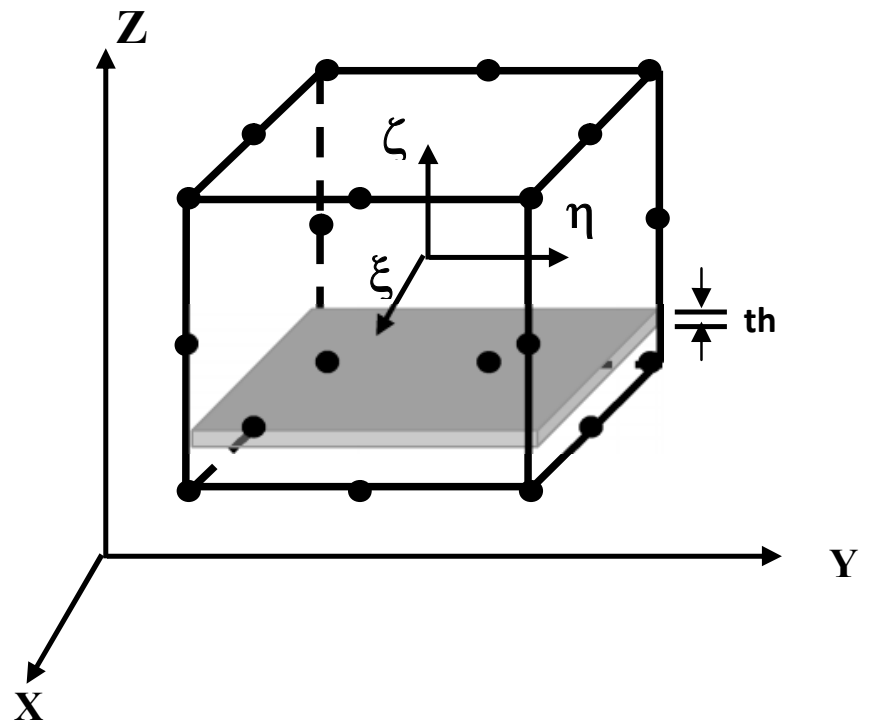

Fig. (3) Twenty-noded isoparametric solid element with reinforcement
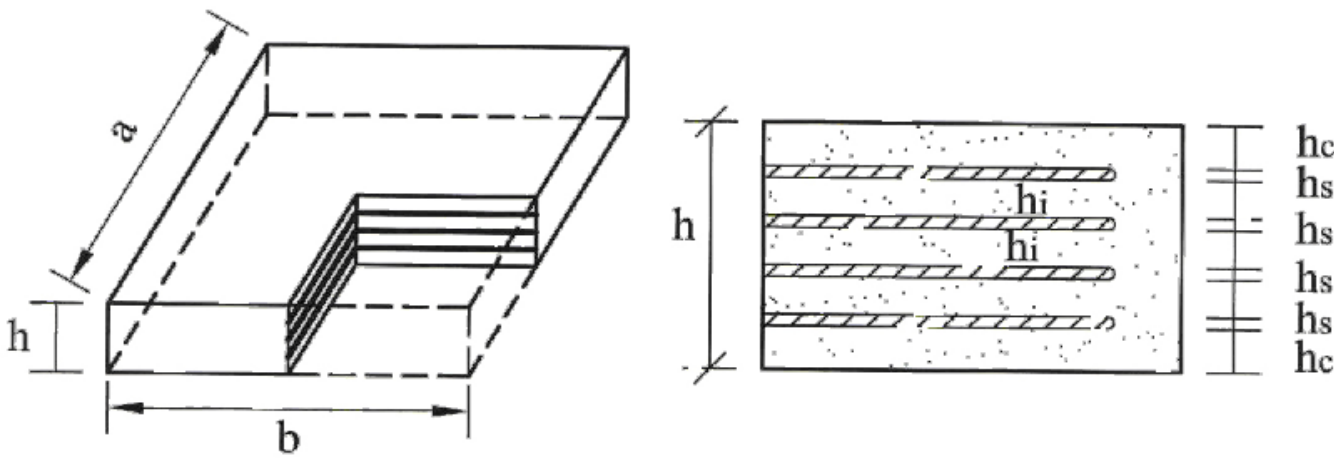
Mahmood : Effect Of Types Of Bearing On The Load Distribution Among Girders

Fig. (4) Components of elastomeric pad bearing

Two approaches are used to represent the elastomeric bearing, these are briefly explained below [13]:

1. Each pad is represented by 3-D finite brick elements with twenty nodes and steel laminates represented by smeared layers. Each layer is located at its exact location at a constant distance from the neutral axis of the element.

The stiffness of these elements, which represent the bearings, is added to the global stiffness of the structure. Perfect bond is assumed between the top nodes of the elastomeric bearing element with the bottom nodes of girder element by assigning the same nodes numbering, while the bottom nodes of the elements representing elastomeric bearing assumed to be fixed. Deformations, strains and stresses for these bearing elements are calculated at different stages of loading.

2. In the second approach a vertical and horizontal springs, with proper stiffness are used to represent the elastomeric supports. The stiffness of these springs are calculated as given below [11]:

$$
\mathrm{K}_{\mathrm{s}}=\mathrm{F}_{\mathrm{s}} / \mathbf{d}_{\mathrm{s}}=\frac{\mathrm{A} \cdot \mathrm{G}}{\mathrm{h}}
$$

$K_{v}=\frac{F_{c}}{d_{c}}=\frac{A \cdot E_{r}}{h}$

Where $A$ is the loaded area.

$\mathrm{G}$ is the shear modulus of rubber.

$\mathrm{h}$ is the total thickness of elastomeric support.

And the effective compression modulus $\left(\mathrm{E}_{\mathrm{r}}\right)$ is given by the relation: 
Mahmood : Effect Of Types Of Bearing On The Load Distribution Among Girders

$E r=E_{0}\left(1+2 \phi S^{2}\right)$

........ (6)

Where $E_{o}$ is the Young's modulus of rubber.

$\varnothing$ is the material compressibility coefficient of rubber

and $\mathrm{S}$ is the shape factor which is given as:

$\mathrm{S}=\frac{\text { Load Area }}{\text { bu lg e Area }}=($ Length $) \times($ Width $) / 2 \cdot h_{\mathrm{i}} \cdot($ Length + Width $)$

(7)

The calculated compression modulus should be multiplied by the following factor: $\frac{1}{1+E_{0} / E_{b}}$

where $E_{b}$ is the bulk modulus of rubber.

Results from this method of calculating compression modulus are summarized graphically in Fig. (5) [11]. This graph can be used to find out the effective compression modulus for the components.

After calculating the values of vertical and horizontal stiffness of these springs, the elastomeric supports replaced by these springs as shown in Fig. (6). These springs are linked with the bottom nodes of the first element of each girder that located at the two ends of the bridge. This is achieved by making the first element size equal to the dimension of the elastomeric support.

In the present study, the numerical integration for evaluating the element matrices is carried out using the 15 -Gauss points rule distributed over the volume the brick element [14].

The nonlinear equations of equilibrium are solved by using an incremental-iterative technique based on the modified Newton-Raphson method in which the tangent stiffness matrix is computed in the first iteration for each load increment. The convergence of the nonlinear solution is controlled by a displacement convergence criterion, where $2 \%$ tolerance is considered.

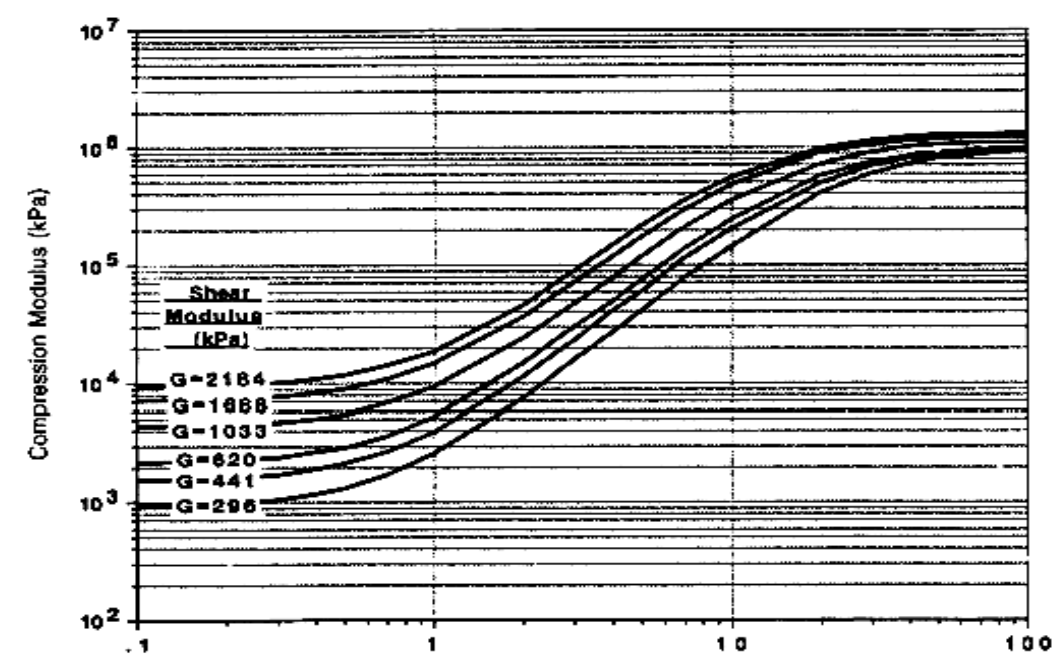


Mahmood : Effect Of Types Of Bearing On The Load Distribution Among Girders

Fig. (5) Compression modulus versus shape factor for various shear modulus [11] .

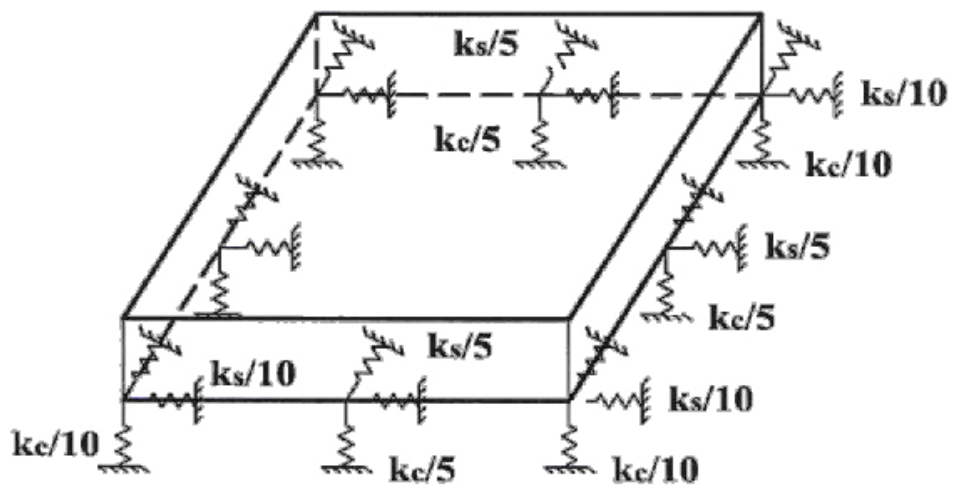

Fig (6) Representing stiffness of bearing by equivalent springs.

\section{Applications and Discussions}

The main objective of the present investigation is to study the effects of boundary conditions at the supports, and its effects on the behaviour of the

bridge. A single span reinforced concrete three-girder bridge has been analyzed by using three types of supports. First one is the simple support represented by hinge at left ends and roller at the right ends of the 
Mahmood : Effect Of Types Of Bearing On The Load Distribution Among Girders

girders, and in the second case the elastomeric support represented by brick elements, while in the third one a simple springs are used to simulate these support.

The bridge chosen for study has been analyzed under single point load placed

at different load positions in addition to the self-weight of the structure. The predicted response of bridge comprises load deflection curves, variation of load distribution factors (LDF) with increasing load, and the reaction components at the different supports.

The bridge has a two lane with an effective span of $21 \mathrm{~m}$, and a total deck width of $8.1 \mathrm{~m}$. Spacing of the three main girders is equal to 2700 $\mathrm{mm} \mathrm{c/c}$ and the total depth of these girders (including the deck slab thickness) is equal to 1800 mm. The two cross beams at the support are assumed to be cast monolithically with the deck slab having for convenience the same depth as that of the main girders. The geometry and details are show in Fig. (7 a-b).

The adopted material properties are summarized in Table (1)

Table (1) Material properties for reinforced concrete bridge.

\begin{tabular}{|c|c|c|c|c|c|c|}
\hline \multicolumn{7}{|c|}{ Concrete \& Steel } \\
\hline $\begin{array}{c}\mathrm{E}_{\mathrm{c}} \\
(\mathrm{MP} \\
\mathrm{a})\end{array}$ & $\begin{array}{c}\mathrm{f}_{\mathrm{c}}^{\prime} \\
(\mathrm{MPa})\end{array}$ & $\begin{array}{c}\mathrm{f}_{\mathrm{t}}^{\prime} \\
(\mathrm{MPa})\end{array}$ & $\begin{array}{c}v \\
(\mathrm{MPa})\end{array}$ & $\begin{array}{c}\varepsilon^{\sharp} \\
(\mathrm{MPa})\end{array}$ & $\begin{array}{c}\mathrm{E}_{\mathrm{s}} \\
(\mathrm{MPa})\end{array}$ & $\begin{array}{c}\mathrm{f}_{\mathrm{y}} \\
(\mathrm{MPa})\end{array}$ \\
\hline $\begin{array}{c}2070 \\
0\end{array}$ & 25 & 3 & 0.2 & 0.0035 & 196200 & 415 \\
\hline \multicolumn{7}{|c|}{ Steel } \\
\hline $\begin{array}{c}\mathrm{E}_{\mathrm{o}} \\
(\mathrm{MPa})\end{array}$ & $v$ & $\begin{array}{c}\mathrm{f}_{\mathrm{c}}^{\prime} \\
(\mathrm{MPa})\end{array}$ & $\begin{array}{c}\mathrm{E}_{\mathrm{s}} \\
(\mathrm{MPa})\end{array}$ & $v$ & $\begin{array}{c}\mathrm{f}_{\mathrm{y}} \\
(\mathrm{MPa})\end{array}$ \\
\hline 4.45 & 0.49 & 20 & 200000 & 0.3 & 345 \\
\hline
\end{tabular}

The analysis has been carried out under six different load positions, each load case being assigned a number from L1 to L6 as show in Fig. (8). The 
Mahmood : Effect Of Types Of Bearing On The Load Distribution Among Girders

of the different sections under study is defined in terms of distance $\mathrm{X}$ from the roller end of the bridge.

The deck slab has been idealized by 72 brick elements, having 9 elements in

the transverse direction with widths equal to $(1.2,0.3,1.2,1.2,0.3,1.2$, $1.2,0.3,1.2) \mathrm{m}$

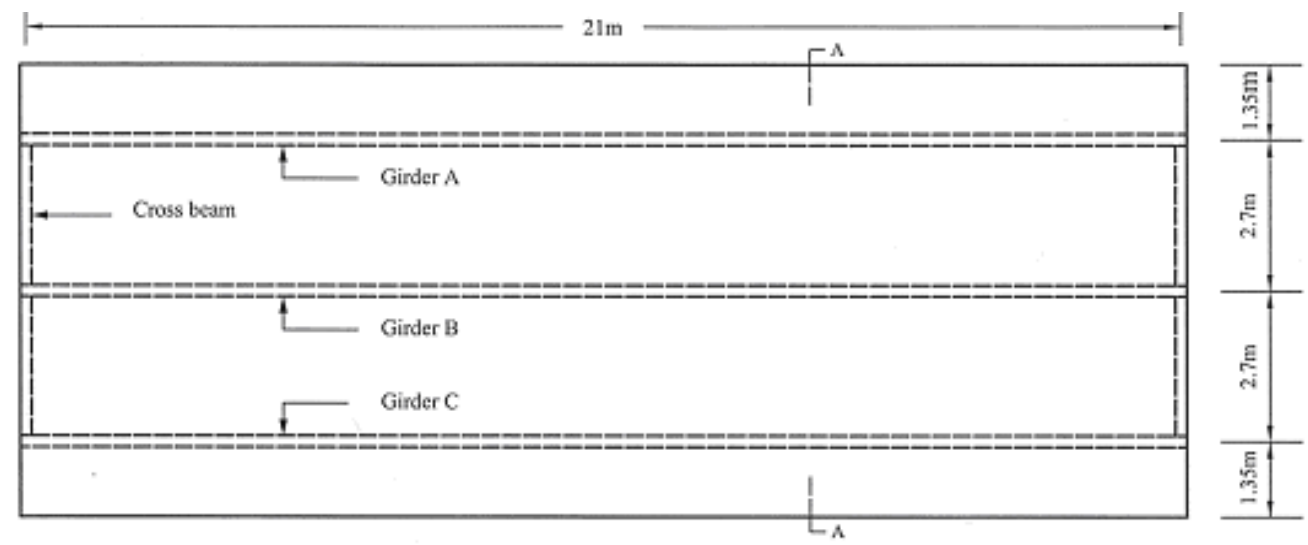

PLAN

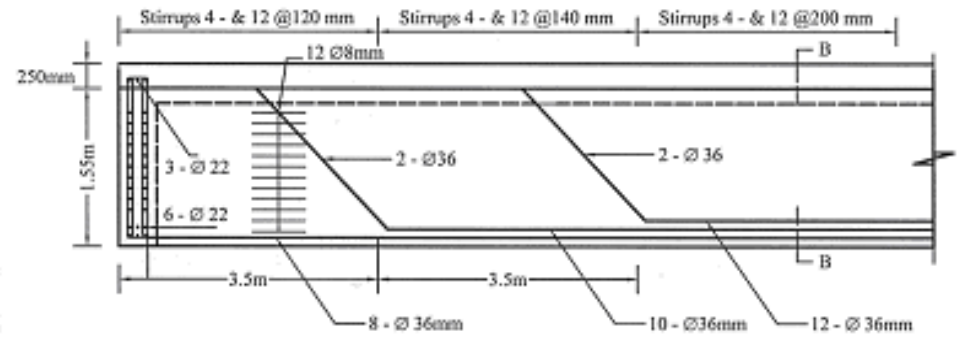

LONGITUDINAL SECTION - MAIN GIRDER B

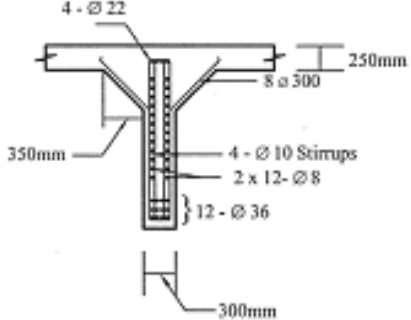

SECTION B-B 
Mahmood : Effect Of Types Of Bearing On The Load Distribution Among Girders

(a)
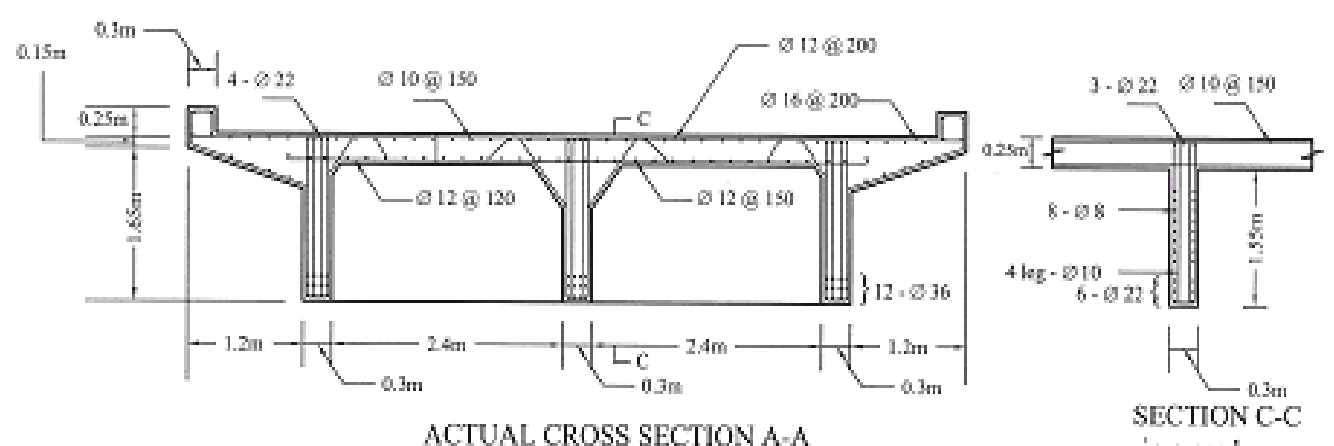

SECTION C-C

ACTUAL CROSS SECTION A-A in cross beam

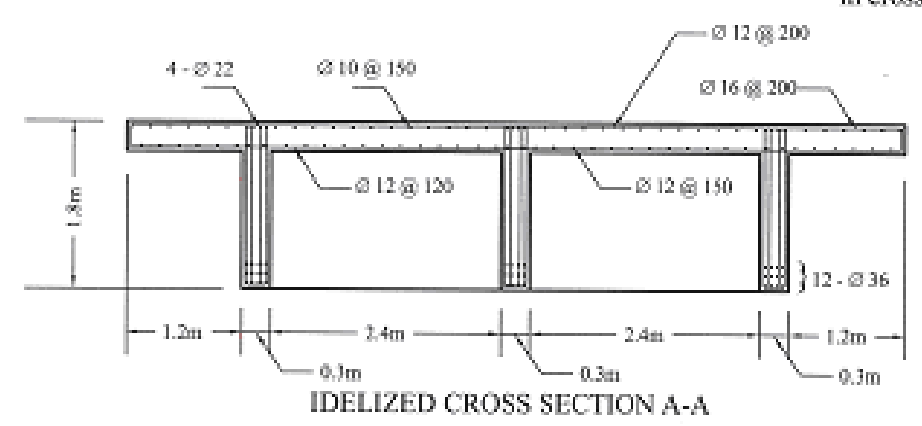


Mahmood : Effect Of Types Of Bearing On The Load Distribution Among Girders

(b)

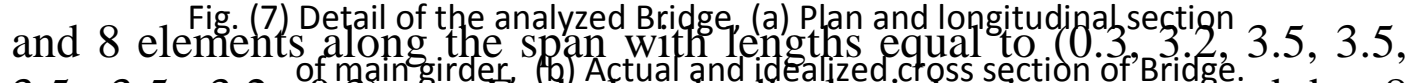
$3.5,3.5,3.2,0.3) \mathrm{m}$. Each A fungitudinal girder is represented by 8 elements along the span, using single element across the depth, while the cross beams have been represented by 2 elements each having $1.2 \mathrm{~m}$ length.

This type of bridge is three-dimensional structure in nature and different boundary conditions at the end support may significantly affects its behaviour [3]. Thus the whole structure has been taken into consideration in the analysis even under symmetrical loading when simple supports (hinge at one end and roller at the other end) are used. When using an elastomeric support or springs support, also the whole structure has been analyzed, in spite of the symmetry of boundary conditions these supports, and that is to compare their response with a simple support bridge.

\section{Elastic Analysis}

For each load case an elastic analysis is carried out for the bridge under a point load of $1000 \mathrm{kN}$. From this analysis, the reaction components have been determined and these are later compared with the same using the nonlinear analysis.

\section{Nonlinear Analysis}

For the six load cases a nonlinear analysis is carried out for the bridge. The structure is first subjected to it's self weight which is applied in a single 
Mahmood : Effect Of Types Of Bearing On The Load Distribution Among Girders

load step, followed by the point load which is applied in several steps varies between

18-23 increments up to failure.

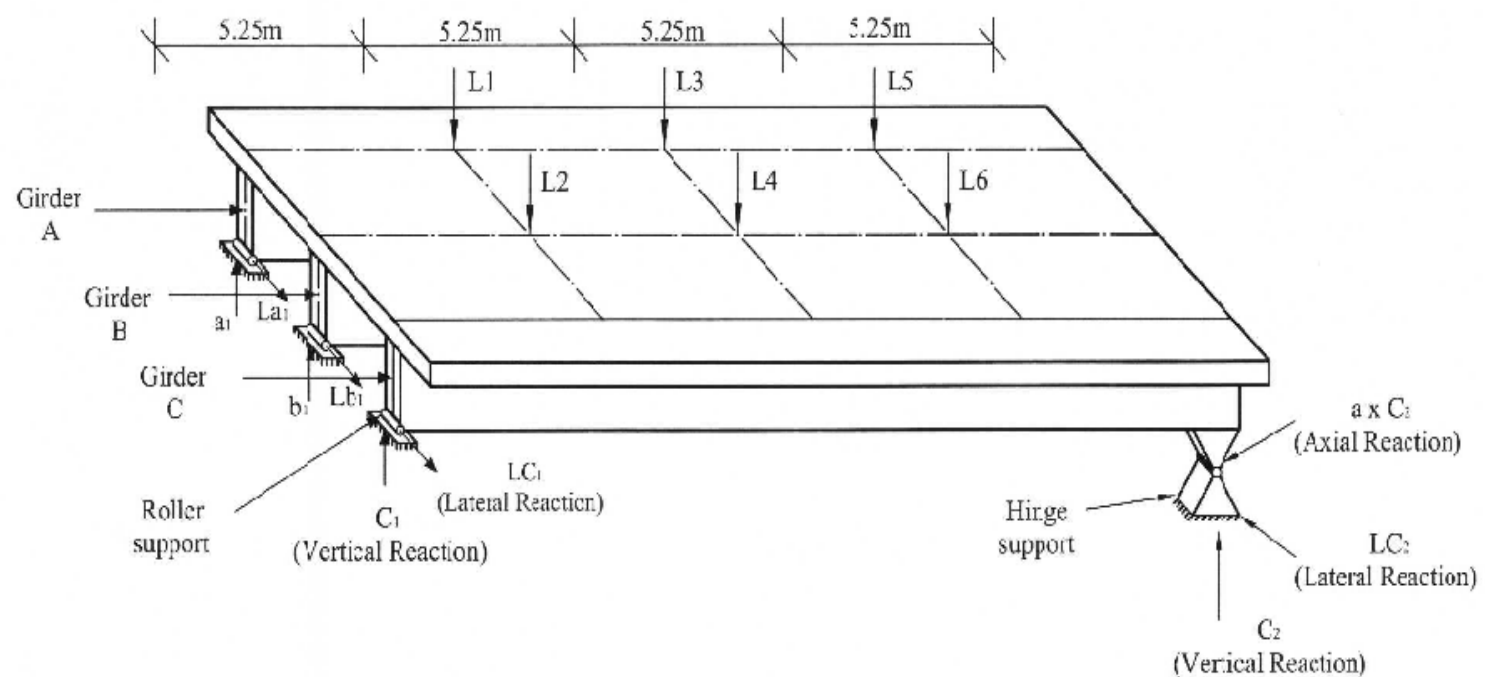

Fig. (8) Positions of single point live load for six different load cases, L1 to L6. 
Mahmood : Effect Of Types Of Bearing On The Load Distribution Among Girders

\section{Load Deflection Curves}

The predicted load deflection curves at the point load position, for the analyzed bridges are show in Figs. ( 9 a - f). These figures show the comparison of load deflection curves for the Bridge with three types of supports, a simple support, an elastomeric support and springs support.

It is seen that, the deflection at the load position in all load cases for bridges having an elastomeric support and springs support is almost identical and it is more flexible compared to the deflection for bridge having a simple support, particularly at an eccentric load cases (L1, L3, L5).

Due to symmetry of boundary conditions at both elastomeric and springs support, it is seen that the deflection for a similarly placed loads L1, L5 and L2, L6 are identical as shown in Figs. (9 a,e) and (9 b,f) respectively, while using a simple support, there is a difference in the deflection for those similarly placed loads (L1 and L5). This may be attributed to the different boundary conditions at the two ends of the bridge, and the axial restraint of the hinge support which causes thereby a reduction in deflections and higher load carrying capacity when the load is close to the hinge support, as shown in Figs. (9 a,e and b,f).

\section{Variation of LDF with Increasing Loads}

The theoretically predicted load distribution factors (LDF) amongst the main girders at different load stages at a selected critical sections are presented

in Figs. (10 a - f) for different types of supports under different load cases. The bending moment in the main girders have been computed by integrating the stress-resultants in concrete as well as in the secondary and main steel. These moments are found first for the dead load, which is the first load step, and under subsequent live load steps. At any particular 
Mahmood : Effect Of Types Of Bearing On The Load Distribution Among Girders

section, the bending moment due to L.L. alone is determine by subtracting the dead load moment from the corresponding total moment. The LDF at any section of a girder $i$ is then determined as:

the ratio of live load L.L. moment in girder $i$ to the average L.L. moment in each girder at that section, this can be expressed as:

LDF in girder $\mathrm{i}=\quad$ L.L. moment in girder $\mathrm{i}$

(total L.L. moment at the section / n)

where $\mathrm{n}$ is equal to the total number of girders.

The variation of LDF under load cases (L1,L2), (L3,L4) and (L5,L6) are given

at sections at distances $7 \mathrm{~m}, 10.5 \mathrm{~m}$ and $14 \mathrm{~m}$ respectively from the roller supports. These sections have been chosen at the Gauss point locations, which are as close as possible to the section where point load is applied. The response of the bridge under different loads is discussed below:

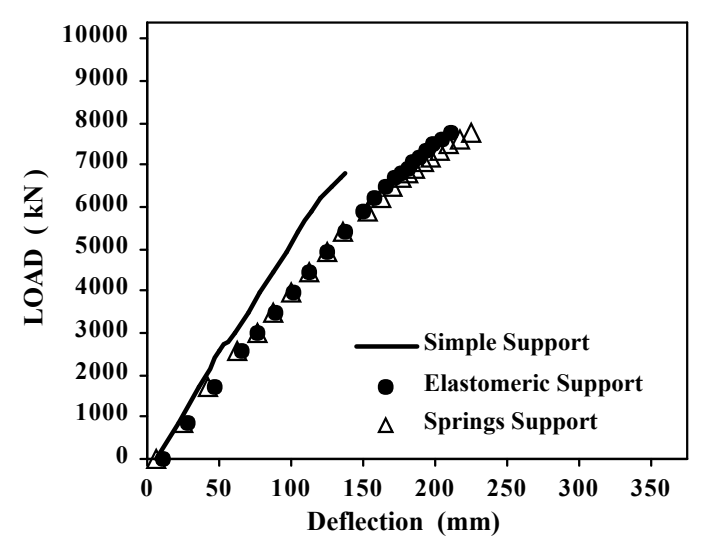

(a) Load case L1

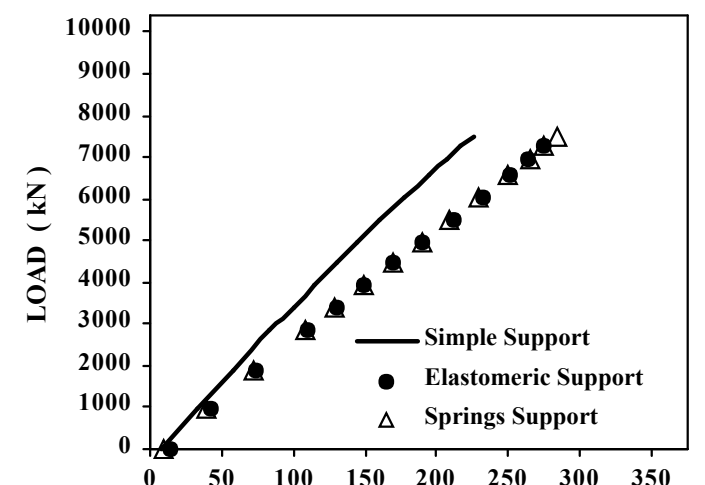

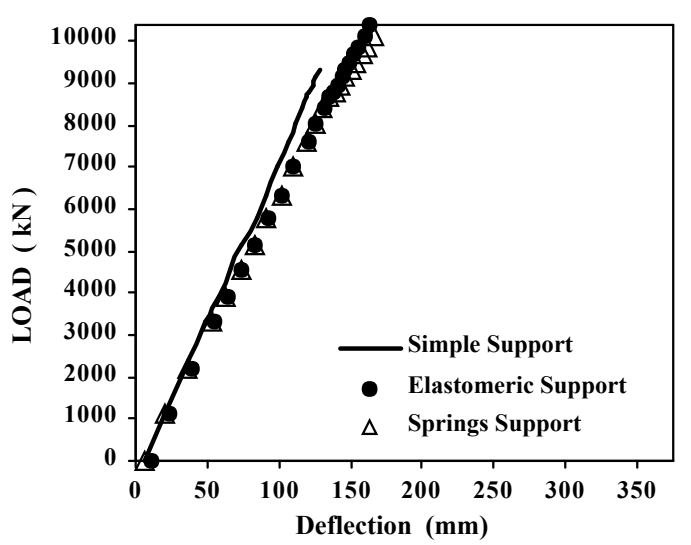

(b) Load case L2

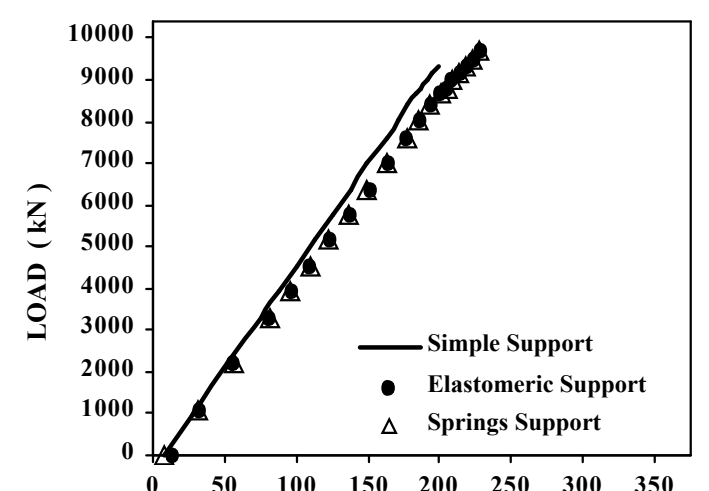


Mahmood : Effect Of Types Of Bearing On The Load Distribution Among Girders 
Mahmood : Effect Of Types Of Bearing On The Load Distribution Among Girders

Load case L1: The variation of the LDF values in the main girders at section

for bridge supported on a simple bearing and bridge supported on elastomeric bearing are shown in Fig. (10 a). It is clear that, when using a simple support, the L.L. carried by the farthest unloaded girder C is almost negligible. The major part of the L.L. (about 66\%) is carried by the loaded girder A. The difference in the LDF of girders A and B is also quite significant through all stages of loading. Although this difference gets slightly reduced at a load of $3026 \mathrm{kN}$ at which yielding of the main steel at this section started. A similar response for the bridge with elastomeric bearing has been predicted except at the elastic stages, where the difference in the LDF values for girders A\&B are less in the elastic stages compared with that of a simple support bridge.

Load case L2: The variation of the LDF values at $7 \mathrm{~m}$ section in the main girders

for different types of bearings are shown in Fig. $(10 \mathrm{~b})$. It is seen that these values in the main girders for both simple and elastomeric support are nearly identical at different stages of loading. It is also clear that the LDF values for the loaded girder B increases up to load of $3916 \mathrm{kN}$, at which yielding of the main steel of girder B is started. This causes a redistribution of the load to the outer girder $\mathrm{A} \& \mathrm{C}$, and the load is almost 
Mahmood : Effect Of Types Of Bearing On The Load Distribution Among Girders

equally distributed amongst the main girders at this section, this remain true up to failure load.

Load case L3: In this case the load placed on outer girder A at mid-span. The load distribution amongst the main girders may seen to be very poor right from early stages of loading up to ultimate load for a simply supported bridge as shown in Fig. $(10 \mathrm{c})$. While using an elastomeric support, the difference of LDF values in the main girders reduces at elastic stages. Also the same can be noticed near ultimate load stages and that is due to the redistribution of the load amongst the main girders.

Load case L4: Fig. (10 d) shows that the response of bridge for the two types of bearings is almost identical up to near ultimate load. The LDF values of loaded girder are reduces at a load of $3916 \mathrm{kN}$, when the main steel at this section start yielding. It can be seen that near ultimate load stages, the difference in the LDF values for the main girders, when using an elastomeric support got reduced due to the redistribution of load to the outer girders A,C at these stages of loading.

Load case L5: In this case, as shown in Fig.(10 e), the values of LDF in the main girders of bridge supported on elastomeric bearings are almost same as that under similarly placed load with respect to the mid-span (L1), and that is due to the symmetry of boundary conditions at these supports. While using simple supports (roller \& hinge), the difference in the LDF values from load case (L1) are quite significant. The difference in the LDF of girders A and B is also quite significant through all stages of

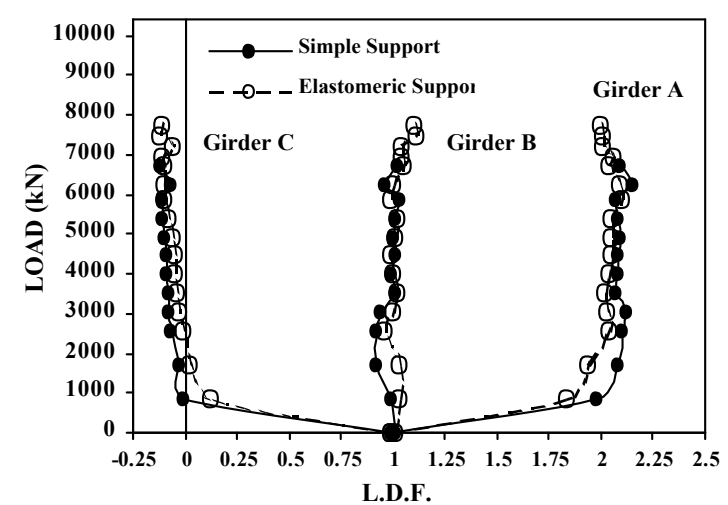

(a) Load case $\mathrm{L} 1$ at section $7 \mathrm{~m}$

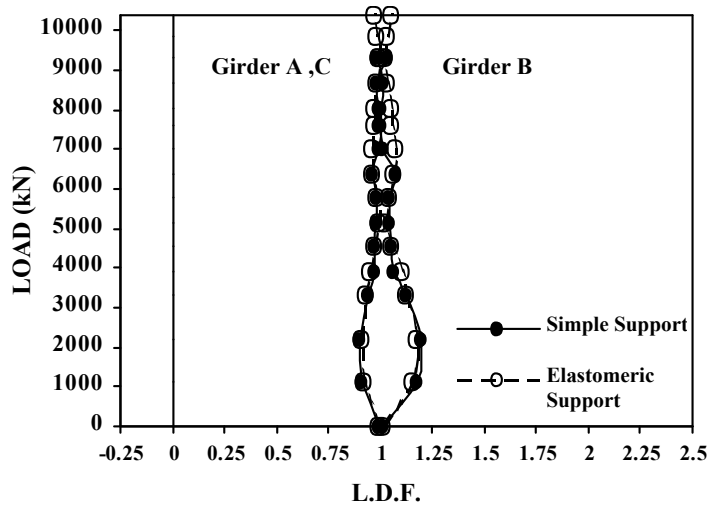

(b) Load case L2 at section $7 \mathrm{~m}$ 
Mahmood : Effect Of Types Of Bearing On The Load Distribution Among Girders 
Mahmood : Effect Of Types Of Bearing On The Load Distribution Among Girders

loading. This may be attributed to the eccentric axial force (axial reaction) at the hinge support which increases when the load moves toward the hinge support. This causes a higher load caring capacity for loaded girder A of the bridge compared with

the symmetrically placed load case (L1). Therefor, in this case the load carried

the other girders (B \& C) is less than that for symmetrically placed load case (L1) for the same bridge.

Load case L6: Figure (10 f) show that the variation of LDF values in the main girders for bridge supported on elastomeric bearings are the same as that under similarly placed load (L2), this is also due to the symmetry of boundary conditions at both ends of the girders. Using a simple support the loaded girder B continue to carry large percent of the load up to failure, although the main steel at this section starts yielding at load $3916 \mathrm{kN}$. The large share of load of this girder is due to the axial restraint at hinge support near this loaded part as pointed out previously.

\section{Vertical Reactions}

In this study the support reactions at the roller and the hinge support of the main girders and reactions for the elastomeric bearings symmetric at both ends of the girder are also predicted at different stages of loading. The theoretically obtained vertical reactions are termed as A1, B1 and C1 at the roller support or first elastomeric support, and as A2, B2 and C2 at the hinge support or second elastomeric support, where characters A, B and $\mathrm{C}$ refer to the girders A, B and C respectively.

These reactions, expressed in terms of the applied external load at the elastic and near ultimate load stages, are shown in Figs. (11 - 12). The distribution of the reactions for the load moving along girder $\mathrm{A}$ are show in figs. (11 a-b) for a simple supports and Figs. (11 c-d) for an elastomeric supports. It can be seen that the reaction components under the three girders at the roller end differ only marginally in the elastic stage from that near failure stage. The reactions A1, B1 at the roller supports becomes almost equal in the post cracking stages when the load passes quarter the span. This is due to the load distribution from the loaded girder A to the adjacent girder B as shown in Fig. (11 a). But reaction components $\mathrm{A} 2, \mathrm{~B} 2$ and $\mathrm{C} 2$ at the hinge support are significantly differ near failure from that in the elastic stage values as shown in Fig. (11 b) particularly when the load is at position $0.75 \mathrm{~L}$. It is interesting to note that reaction under girder $\mathrm{C}$ is negative at the hinge end only when the load moves on the outer girder A. Figs. (11 c-d) show the symmetry in the reactions under the three girders for both ends of the elastomeric supports and this is due to symmetry of the boundary condition at these ends. From these figures it is seen that the reactions at 
Mahmood : Effect Of Types Of Bearing On The Load Distribution Among Girders

the first and second elastomeric support differ slightly from the elastic stage to that near failure stage.

The numerically predicted vertical reaction when the load moves on the central girder B are shown in Figs. (12 a-b) for the roller and the hinge support respectively, and Figs. (12 c-d) for both first and second elastomeric support which are symmetric at the ends. The roller reactions in the elastic stage and near failure are nearly the same under all the girders, whereas the vertical reaction at the hinge end under the loaded girder B in the post cracking stages is less than that in the elastic stages, when the load at position $0.75 \mathrm{~L}$ in particular, and this due to the load distribution from the loaded girder B to the outer girders $\mathrm{A}, \mathrm{C}$ at the same section due to the reduction in it's stiffness. The reactions at the first and the second elastomeric support are nearly same under all the girders in the elastic stages and near failure as shown in Figs. (12 c-d) .

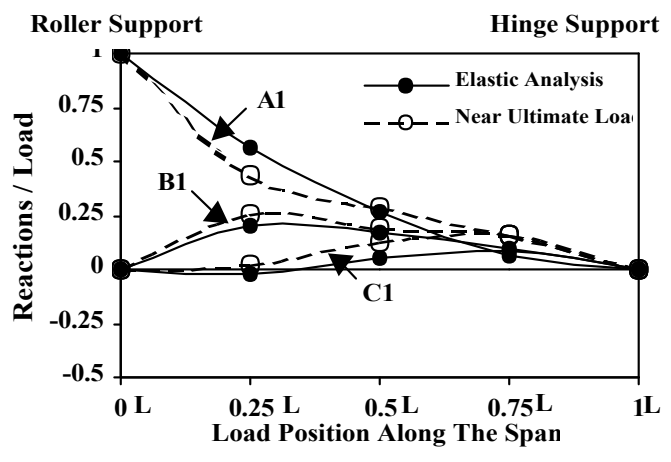

(a) Roller support

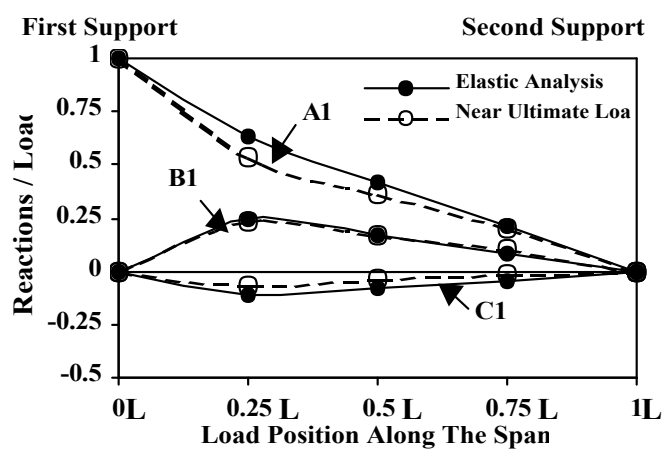

(c) First elastomeric support

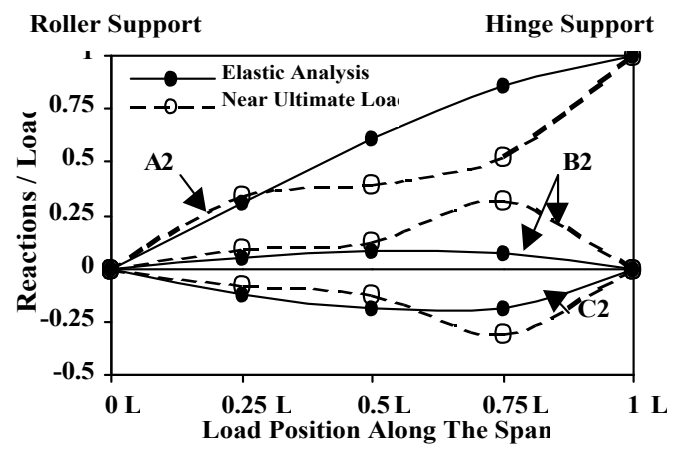

(b) Hinge support

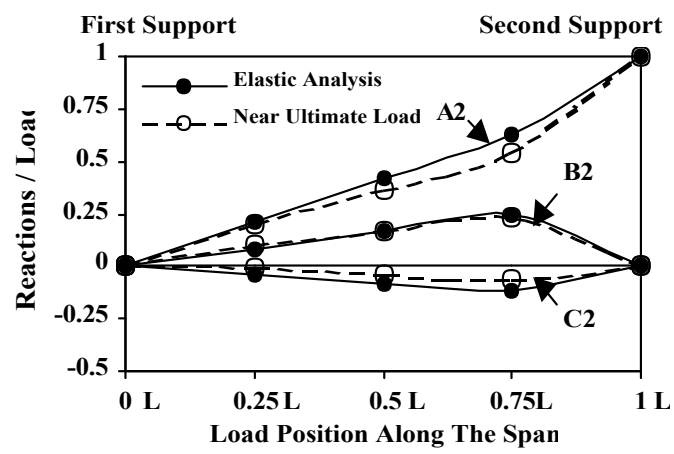

(d) Second elastomeric support

Fig.(11) Variation of support reactions with load moving on Girder A of Bridge.

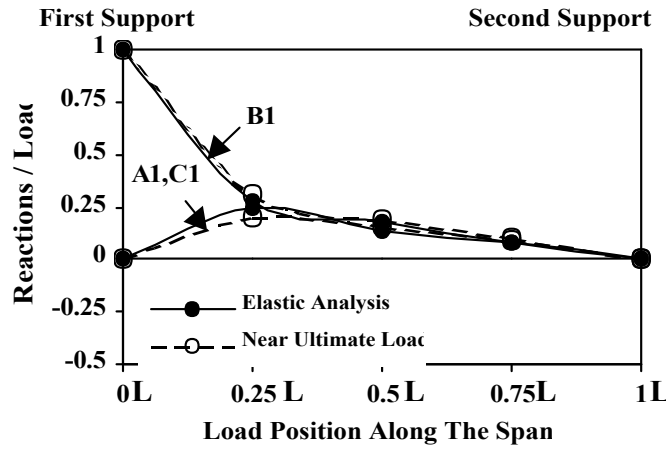

(a) Roller support

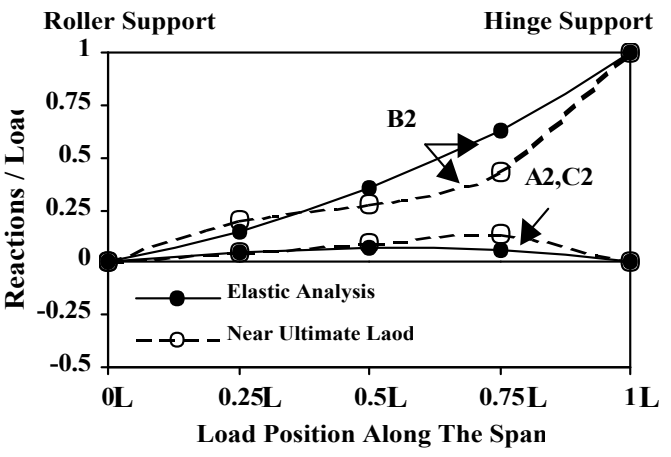

(b) Hinge support 
Mahmood : Effect Of Types Of Bearing On The Load Distribution Among Girders

\section{Conclusions}

The method presented in this study is capable to idealize the T-beam Bridge close to it's actual physical structural properties. Based on the analytical results and critical discussion of the results the followings can be concluded:

1. The load-deflection curves for bridge supported on elastomeric supports and springs support are almost identical and shows more flexibility compared to the load-deflection curves for bridge supported on a simple supports especially at an eccentric load cases (L1, L3, L5).

2 . The different boundary conditions at the ends of the simply supported bridge causes unsymmetrical behaviour of bridge under symmetrically placed loads. This is due the axial restraining at the hinge support which causes a reduction in the deflection and increasing ultimate load capacity when the load is in the vicinity to the hinge supports.

3. For the cases when the load approaching the hinge support, the distribution of the load amongst the main girders at the loaded section, using an elastomeric support, is better than that of the classical hingeroller support.

\section{References}

1. Bakht, B. and Jaeger, L. G., "Bearing Restraint In Slab-on-Girder Bridges", Journal of Struct. Engng. Vol. 114, No. 12, Des 1988. 
Mahmood : Effect Of Types Of Bearing On The Load Distribution Among Girders

2. Kassim, M., Tarhini and Geraled, Frederic R., "Load Distribution on Highway Bridges Using ICES-STRUDL Finite Element Analysis", Computers and Struct. Vol. 32, No. 6, 1989, PP. 1419-1428.

3. Mahmood, M. N., "Investigation of Post-Cracking Behaviour of Reinforced Concrete Girder Bridge", Ph. D. Thesis, University of Roorkee, India, 1994, 247, PPs.

4. Kwasniewski, L., "Sensitivity Analysis for Slab-on-Girder Bridges", $8^{\text {th }}$ ASCE Special Conference on Probabilistic Mechanics and Structural. Reliability PM 2000-319.

5. Embabi, M. S. and Cope, R. J., "An Equivalent Elasto-Plastic Constitutive Model for Biaxially Loaded Concrete", Proceeding of International Conference on Computer Aided Analysis and Design of Concrete Structures, Pineridge Press Limited, Swansea, 1984, PP. 275288.

6. Cervera, M. and Hinton, E., "Nonlinear Analysis of Reinforced Concrete Plate and Shell Structures" Using 20-Noded Isoparamtric Brick Elements", International Journal of Computers and Structures, Vol. 25, No. 6, 1987, PP. 845-869.

7. Owen, D. R. J. and Hinton, E., "Finite Element in Plasticity: Theory and Practice", Pineridge Press Limited, Swansea, U.K., 1980.

8. Vector, D. T., "Essentials of Bridge Engineering", Fourth Edition, Oxford and IBH Puplishing Co. Pvt. Ltd. 1991.

9. Lakes, R. S., "Design Considerations for Negative Poisson's ratio Materials" ASME Journal of Mechanical Design, 115, 1993, PP. 696-700.

10. Lindley, P. B., "Engineering Design With Rubber", MRPRA, Table 3, P. 8, 1978 .

11. Gent, A. N., "Engineering With Rubber : How to Design Rubber Components", $2^{\text {nd }}$ edition, CH. 8, Jun. 2001, PP. 224-232.

12. Zienkiewics, O. C., "The Finite Element Method", McGraw-Hill, Third Edition, London, 1977.

13. Jallo, E.K., "Effect of Types of Bearing on the Load Distribution Among Girders of the Bridge", MSc. Thesis, University of Mosul, Iraq, 2004

14. Irons, B. M., "Quadrature Rules for Brick-Based Finite Elements", Investicational Journal for Numerical Methods in Engineering, Vol. 3, 1971 , PP. 293-294. 
Mahmood : Effect Of Types Of Bearing On The Load Distribution Among Girders 